clinicians' perceptions of the quality of clinical trauma care delivered in New Zealand's only regional trauma system.

Methods An anonymous online survey of clinicians providing trauma care in five hospitals in the Midland region of New Zealand was conducted in 2014. The region has a population of around 799,000 people and a predominantly rural environment. The survey sought information on clinicians' perceptions regarding: their level of comfort in managing trauma; awareness of regional and local trauma care guidelines; quality of trauma care at their hospital and the region; presence/absence of inequities in care; and the potential benefits of Computerised Decision Support Systems (CDSS).

Results 23\% (74/319) of clinicians invited took part, the majority of whom were medical specialists, had $>5$ years of experience treating trauma patients, and attended to trauma patients less than twice weekly. Linear regression analyses indicated that having $>5$ years of experience treating trauma patients $(p=0.04)$ and holding a senior position $(\mathrm{p}=0.04)$ were significant predictors in clinicians' comfort level in managing major trauma patients. Two-thirds of clinicians felt there were gaps in trauma care delivery in both their hospital and the Midland region with senior clinicians more likely to give a lower rating to the quality of the regional system. $35 \%$ of clinicians 'often/very often' experience difficulty in engaging with relevant specialities for trauma patients. Over $75 \%$ of respondents answered 'rarely'/'never' when asked how often their healthcare organisation treats people unfairly based on a range of factors (e.g. ethnicity, socioeconomic status). While their direct experience with CDSS was minimal, over half the clinicians considered CDSS to be a useful tool to guide the diagnosis and management of trauma patients.

Conclusion The study has highlighted some perceived gaps in trauma care in the region, and a lack of confidence among junior clinical staff in managing trauma patients. An opportunity exists to investigate the integration of CDSS into clinical trauma care to help guide the delivery of evidence-based care.

\section{Safety Culture}

\section{Post Mon 1.19}

\section{IMPROVING SAFETY CULTURE IN A MULTIPROFESSIONAL NETWORK - FROM POLICY TO PRACTICE}

${ }^{1}$ Pirjo Lillsunde, ${ }^{2}$ Hannele Häkkinen, ${ }^{3}$ Heikki Laurikainen, ${ }^{4}$ Maija Peltokangas, ${ }^{5}$ Merja Vahva, ${ }^{6}$ Ulla Korpilahti. ${ }^{1}$ Ministry of Social Affairs and Health; ${ }^{2}$ The Association of Finnish Local and Regional Authorities; ${ }^{3}$ Finnish National Rescue Association; ${ }^{4}$ Ministry of the Interior; ${ }^{5}$ Ministry of Transport and Communications; ${ }^{6}$ National Institute for Health and Welfare

\subsection{6/injuryprev-2016-042156.600}

Background The Finnish safety culture in working life and in traffic has improved as well as the safety of children. A good safety culture needs to be extended to all environments and prevention belongs for everyone. The multi-sectoral coordination group in Finland has drawn up a National Target and Action Programme for the Prevention of Home and Leisure Accident Injuries 2014-2020.

Description of the problem Young and middle-aged men are over-represented in the statistics on home and leisure accident injuries. The growing number of elderly people and independent living pose challenges the safety culture. The high levels of alcohol consumption and binge drinking increase the accident risk.
Results Municipalities, National Institute for Health and Welfare, Finnish National Rescue Association, social and health care service providers and housing companies have increased safety assessments as a part of the structures, planning, management systems, decision-making and activities of organisations like schools, day-care centres and hospitals. Ministry of Social Affairs and Health (MSAH), Finnish Institute of Occupational Health and Centre for Occupational Safety have included the home and leisure accident prevention as a permanent part of safety work at workplaces. MSAH, Ministry of the Interior, Ministry of Transport and Communications and non-governmental organisations continue the efforts to intensify cooperation across the accident prevention sector. Finnish Defense Forces, Finnish Road Safety Council, sports clubs and leisure time organisations are engaged in the work to prevent accidents in various environments and activities into account in the preventive efforts.

Conclusion Number of injury deaths in Finland show decreasing trends. The prevention activity has to be permanent and long lasting and targeted well for all age group and different environments. Non-governmental organisations are important in implementing actions in the practice.

\section{FINNISH TRANSPORT AGENCY'S OCCUPATIONAL SAFETY CULTURE - MAPPING THE DEVELOPMENT PHASE IN 2016}

Milka Ukkonen. Laurea University of Applied Sciences, Finland

\subsection{6/injuryprev-2016-042156.601}

Background The mapping of the Finnish Transport Agency's (FTA) occupational safety culture, or more briefly 'OS culture', will be conducted as a thesis project starting in January 2016. The project is carried out in cooperation with FTA, Laurea University of Applied Sciences and Finnish Institute of Occupational Health. The research's aim is to develop FTA's OS culture by defining its development phase.

Methods The mapping will be focused on FTA's employees whose job description includes working at the worksites. The mapping will be executed through qualitative research method with interviewing the target group by using the standardised, open-ended interviews as well as surveys for cross-checking. The discussed factors in the research include the control of occupational safety (norms, instructions and procedures) and the safety management (managing human factors, creating a culture by leadership). The interview compilations will be brought to the target group for evaluation in a workshop to gain constructive and comprehensive data.

Results The mapping's results will define the target group's OS culture's development phase and its level; positive, negative and neutral factors and how to develop the OS culture. These issues will be discussed from two points of views; the development phase in FTA's and in its employees' operations. Based on the results the thesis will give concrete suggestions on how to proceed to develop the OS culture. The mapping will be compared with earlier similar researches' methods and results to gain value and versatile insight for the mapping and to create the possibility for other fields of expertise to utilise the data.

Conclusions The thesis project will be finished and the mapping's results released in August 2016. Through the cooperation amongst the parties the results are to gain information on OS culture for advance and support the development of new procedures not just in FTA but also for other fields of industries. 


\section{A SHOPPING CENTRE SECURITY GUARD THAT WORKS WITH YONGSTERS WITH MORE UNDERSTANDING AND TOOLS}

Pauliina Lampela. Nuorten Palvelury, Finland

10.1136/injuryprev-2016-042156.602

Background In Finland many youngsters hang out with their friends in shopping centres. To some of them a shopping centre can be the most important space of their social life.

Nuorten Palvelu ry is a national non-governmental organisation in Finland. Since 2010 the organisation has worked in cooperation with different companies and commercial property owners. The aim is to enhance youngsters' wellbeing in commercial spaces and also develop the communication and understanding between youngsters and the adults who work in these spaces. Methods Include e.g. educating shopping centre security guards interact better with youngsters.

Description of the problem Security guards encounter a lot of youngsters in shopping centres. There is a need for a new kind of profession that has more knowledge, tools and worktime to interact and work with the youngsters who spend a lot of time in shopping centres. Youngsters are a specific target group in how much a single adult can affect their lives in both positive and negative ways. There is a little or no education in this matter in the official education of security guards in Finland.

Results A security guard with more understanding, tools and worktime will work as one of the security guards in a shopping centre in Southern Finland for 4 months in the beginning of year 2016. Nuorten Palvelu ry will educate and supervise him prior and during this experiment. This is done in close cooperation with the employer of the security guard (Securitas Oy) and the shopping centre manager (Citycon Oyj). By the Safety2016 conference we will have the results of the experiment. The security guard will continue his work after the 4 month period if the practice proves needed.

Conclusions This is a new kind of practice of private security profession that has proven needed by youngsters, security guards and shopping centre managers. The aim is to create a form of work that can be spread out to other shopping centres after this experiment.

\section{MODIFYING HUMAN FACTOR TOOL FOR WORK PLACES - DEVELOPMENT PROCESSES AND OUTPUTS}

Anna-Maria Teperi. Finnish Institute of Occupational Health, Finland

\subsection{6/injuryprev-2016-042156.603}

Background Awareness of human factors (HF) as a key safety factor has increased in recent decades. Several methods and tools have been designed to better master HF at workplaces, but the focus of them has, however, remained at human-machine and human-system interfaces. Yet, the latest safety research stresses the organisational and systemic view, to improve the capability of organisations to be proactive, and to act and react in undesired safety critical events.

Description of problem In technical, predominantly male domains in particular, competence in handling HF at workplaces may be weak. HF is not included in technical profession training, despite the fact that these professions often manage safety at workplaces. HF issues may be considered too challenging to raise. As safety is not only promoted through technical solutions and norms, competence in HF would add value to safety work. Practical HF tools should be used and modified in order to better handle this field at workplaces.

Results This presentation describes the modification of an HF tool for different professional fields. Originally, an HF tool was designed for Finnish Air Traffic Management, to support the skills of operative personnel and management to analyse the individual-, group-, work- and organisational success and weakness factors behind operative incidents. The HF tool was next modified and tested by an education department, a rescue and firefighting department and an energy production organisation of a city organisation. The latest implementations have been made in the nuclear industry and in the maritime, for operational event and safety culture analysis. Development processes and outputs of the HF tool modifications are summarised and evaluated.

Conclusions Concrete HF models and tools are needed, in order to be able to more effectively learn and analyse the human contribution to safety. Both the successes and weaknesses of HF must be included in these models. Validation of the HF tool is to be continued, and user-friendly applications of the tool are being designed.

\section{AN EXAMINATION OF SAFETY CLIMATE AND SEAT BELT USE IN THE FIRE SERVICE}

${ }^{1}$ Todd D Smith, ${ }^{2}$ David M DeJoy, ${ }^{3}$ Mari-Amanda (Aimee) Dyal . 'Indiana University School of Public Health - Bloomington; ${ }^{2}$ University of Georgia, College of Public Health; ${ }^{3}$ Kennesaw State University

\subsection{6/injuryprev-2016-042156.604}

Background Historically, motor vehicle incidents account for between one-fifth to one-third of all firefighter fatalities in the United States. Non-use of seat belts has resulted in many of these fatalities. Bolstering the use of seat belts is a major goal of the emergency services field.

Methods Data were collected from 208 career firefighters working for a city fire department in the southeastern United States. Preliminary analyses assessed seat belt use. Structural equation modelling was then used to assess the relationships between safety climate and seat belt use.

Results In our sample, $78.7 \%$ indicated they almost always wear their seat belt when riding in fire apparatus or other emergency vehicles. $17.4 \%$ indicated they often wear their seat belt and $3.4 \%$ reported that they sometimes use their seat belt. Use did not significantly differ between varying age groups, race, marital status, education level, years of fire service work or rank. A posited model was examined. Positive perceptions of workgroup safety climate were positively associated with seat belt use. Organisational level safety climate did not have a significant relationship with seat belt use, but did positively influence workgroup safety climate perceptions.

Conclusions Safety climate has been associated with safety compliance and participation behaviours, but no work has specifically examined the impact of safety climate on seat belt use in firefighters. This study shows that work group level safety climate is a significant predictor of seat belt use $(p<0.01)$. Companies within fire departments can bolster safety climate with supportive supervisors and by enhancing group cohesion among firefighters and between firefighters and company officers. When firefighters perceive these positive factors, they are more likely to use seat belts, which enhances firefighter vehicle incident survival rates. 